08

\title{
Кинетика и механизмы УФ индуцированного формирования наночастиц золота в растворах хитозана, допированных $\mathrm{HAuCl}_{4}$
}

\author{
(C) Т.А. Грачева, Т.А. Кузьмичева, В.Н. Перевезенцев, Л.А. Смирнова, \\ A.Е. Мочалова, Е.В. Саломатина
}

Нижегородский государственный университет им. Н.И. Лобачевского, 603950 Нижний Новгород, Россия

e-mail: grata04@mail.ru

(Поступило в Редакцию 19 сентября 2016 г.)

\begin{abstract}
Методами оптической спектроскопии и малоуглового рассеяния рентгеновских лучей исследована кинетика УФ индуцированного формирования наночастиц золота в водно-кислотных растворах хитозана, допированных $\mathrm{HAuCl}_{4}$, начиная с самых ранних стадий. Показано, что в процессе синтеза при непрерывном увеличении средних размеров наночастиц от 2.9 до $6.3 \mathrm{~nm}$, максимум плазмонного резонанса смещается в сторону меньших длин волн от 535 до $523 \mathrm{~nm}$, в то время как для полностью сформировавшихся ансамблей наночастиц наблюдается обратная зависимость. Экспериментально установлено изменение формы кривых распределений частиц по размерам в процессе синтеза, и путем анализа „обратной задачи“ сделаны выводы о доминирующих механизмах роста наночастиц.
\end{abstract}

DOI: 10.21883/JTF.2017.08.44729.2036

\section{Введение}

Сегодня не уменьшается поток публикаций, в которых главными объектами исследования являются металлические наночастицы (НЧ) и композиционные материалы на их основе. Появляются обширные обзоры, посвященные современным методам синтеза, уникальным свойствам, структуре и механизмам формирования НЧ металлов [1-4]. Особое внимание уделяется НЧ золота - с одной стороны, их можно рассматривать как модельные объекты при описании наносистем, с другой стороны, они удобны для тестирования новых современных методов диагностики структуры и свойств, которые позволяют получать более полную и корректную информацию и развивать существующие представления о металлических НЧ [5-7]. Подчеркивается огромный потенциал их использования в современных технологиях в качестве сенсоров, оптически-нелинейных сред, биологически активных агентов, а также в медицинских приложениях, связанных как с диагностикой и терапией раковых клеток, так и с транспортировкой лекарств к различным органам и тканям $[8,9]$. Активный научный интерес означает, что в обсуждаемой области существует достаточно много нерешенных, дискуссионных вопросов.

Актуальными в области создания функциональных материалов, модифицированных НЧ, остаются вопросы изучения кинетики и механизмов формирования металлических НЧ, начиная с самых ранних стадий. К сожалению, в большинстве исследований приводится лишь качественное описание процессов, основанное на изменениях оптических спектров системы, происходящих при зарождении и росте НЧ [10-14].

Одновременно с этим активно развиваются методы компьютерного моделирования для анализа процессов формирования НЧ металлов в различных технологических схемах синтеза [15-17]. Чаще всего в качестве среды, в которой синтезируются частицы, выбирают однородные среды (газ или жидкость). При этом во многих публикациях, описывающих модели зарождения и роста НЧ, отсутствует анализ кинетических данных, что накладывает существенные ограничения на применимость этих моделей. До сих пор не существует единого мнения о механизмах и структурных моделях формирования НЧ золота даже для хорошо изученного цитратного метода синтеза [3].

Механизм синтеза металлических НЧ в общем виде может быть описан последовательностью нескольких основных этапов, каждый из которых имеет свои термодинамические и кинетические характеристики [2-18]. Например, к первому этапу можно отнести непосредственно химическую реакцию восстановления иона металла, а последующие будут отражать рост металлической частицы от атома до НЧ. Согласно [19], формирование металлической НЧ может протекать по двум механизмам: последовательному и параллельному. Для последовательного роста характерно увеличение размеров частиц за счет присоединения отдельных атомов к образовавшемуся равновесному зародышу. Параллельный механизм характеризуется образованием кластеров за счет первоначального объединения атомов в димеры, димеров в тетрамеры, тетрамеров в октомеры и т.д. Дальнейший рост НЧ обусловлен коалесценцией и коагуляцией кластеров. Авторами [20] показано, что в зависимости от механизма, который реализуется, меняется форма кривых распределения НЧ по размерам. Решая обратную задачу, по виду распределений можно сделать вывод о механизмах формирования НЧ. 


\section{Материалы и экспериментальные методы}

В настоящей работе методами оптической спектроскопии и малоуглового рассеяния рентгеновских лучей (МУРР) изучался процесс УФ индуцированного формирования НЧ Аu в уксусно-кислом растворе хитозана, допированном $\mathrm{HAuCl}_{4}$. Оптическая спектроскопия является надежным экспресс-методом изучения процессов синтеза НЧ золота и по существу единственным на ранних стадиях их формирования. По появлению и нарастанию максимума плазмонного резонанса (ПР), характерного для НЧ $\mathrm{Au}\left(\lambda_{\max }=520-540 \mathrm{~nm}\right)$, можно судить о времени формирования устойчивой системы НЧ, высота пика ПР прямо пропорциональна концентрации НЧ. Метод МУРР весьма эффективен при исследовании кинетики процесса формирования НЧ золота в полимерных матрицах. Важным преимуществом данного метода является следующее: пробы для исследования, отобранные на любом этапе синтеза (это могут быть коллоидные растворы или пленки), не требуют специальной подготовки и не подвергаются дополнительным воздействиям, которые могут привести к изменению структуры; кроме того, НЧ золота обладают высоким рентгеновским контрастом, что позволяет регистрировать рассеяние при малых временах синтеза, когда концентрация НЧ сравнительно невелика; и наконец, метод МУРР позволяет получать достаточно полный набор геометрических характеристик, включая распределение НЧ по размерам $f(d)[21]$.

Способ синтеза, материалы, экспериментальное оборудование, применяемые в работе, подробно описаны в [5]. Синтез НЧ в растворе хитозана инициировался УФ облучением. Время УФ воздействия $t_{U V}$ для исследуемых образцов варьировалось в интервале от 3 до $120 \mathrm{~min}$. В таблице приведены маркировка образцов (столбец М), в которой первая цифра обозначает $t_{U V}$ в min, а вторая - время дополнительного температурного воздействия $t_{T}$ при $T=60^{\circ} \mathrm{C}$ в $\mathrm{h}$, а также характеристики оптических спектров: $\lambda_{\max }-$ положение максимума поглощения, $A / A_{0}-$ относительная интенсивность, нормированная на максимальное значение.

\section{Результаты исследований и их анализ}

Рассмотрим изменение структуры полимерных дисперсий на основе хитозана, допированных $\mathrm{HAuCl}_{4}$ от времени. Характерные оптические спектры образцов приведены на рис. 1. Как видно из рис. 1, $a$, на кривых, соответствующих малым временам УФ облучения, присутствует ярко выраженный максимум I $\left(\lambda_{\max } \approx 225 \mathrm{~nm}\right)$, характерный для иона $\mathrm{AuCl}_{4}^{-}$. В процессе УФ облучения происходит каскад реакций внутримолекулярного восстановления золота до атомарного состояния, количество анионов $\mathrm{AuCl}_{4}^{-}$уменьшается, соответственно
Характеристики исследуемых образцов

\begin{tabular}{r|r|r|r|r|r|r|r|r}
\hline \multirow{2}{*}{ № } & \multirow{2}{*}{$\mathrm{M}$} & \multicolumn{2}{|c|}{$\lambda_{\max }, \mathrm{nm}$} & \multicolumn{2}{|c|}{$A / A_{0}, \%$} & \multirow{2}{*}{$d, \mathrm{~nm}$} & $R(d)$ & $R(\lg d)$ \\
\cline { 3 - 6 } & & $\mathrm{I}$ & $\mathrm{II}$ & $\mathrm{I}$ & $\mathrm{II}$ & & & \\
\hline 1 & $0-0$ & 225 & - & 100 & - & - & & \\
2 & $3-0$ & 224 & - & 66 & - & - & & \\
3 & $6-0$ & 225 & 535 & 46 & 5 & - & & \\
4 & $9-0$ & 225 & 535 & 25 & 9 & - & & \\
5 & $12-0$ & 224 & 535 & 14 & 11 & - & & \\
6 & $15-0$ & 224 & 535 & 12 & 18 & 2.9 & 0.971 & 0.997 \\
7 & $60-0$ & 224 & 532 & 4 & 45 & 4.5 & 0.967 & 0.982 \\
8 & $120-0$ & - & 529 & - & 84 & 6.1 & 0.978 & 0.966 \\
9 & $120-1$ & - & 523 & - & 100 & 6.3 & 0.981 & 0.974 \\
10 & $120-2$ & - & 523 & - & 100 & 6.3 & 0.992 & 0.977
\end{tabular}

интенсивность максимума I падает. После 6 min УФ воздействия регистрируется слабая полоса поглощения II с максимумом в области $\lambda_{\max }=520-540 \mathrm{~nm}$, который обусловлен поверхностным плазмонным резонансом. На рис. $1, b$ представлено относительное изменение интенсивности пиков I и II при малых временах синтеза. В течение первых $12 \mathrm{~min}$ УФ воздействия происходит интенсивное восстановление золота, сопровождающееся уменьшением пика $\mathrm{AuCl}_{4}^{-}$на $87 \%$, при этом доля $\mathrm{HЧ}$ составляет $12 \%$ от максимального значения.

Как видно из таблицы и рис. 2, дальнейшее облучение сопровождается активным нарастанием пика ПР, что свидетельствует о значительном увеличении количества НЧ золота. С течением времени происходят незначительное уменьшение ширины и смещение максимума ПР в сторону меньших длин волн. Процесс формирования НЧ заканчивается после УФ облучения в течение $120 \mathrm{~min}$ и прогрева в течение $1 \mathrm{~h}$. Дальнейшая выдержка при температуре $60^{\circ} \mathrm{C}$ не изменяет форму и положение пика II.

Результаты исследований методом МУРР приведены на рис. 3. Следует отметить, что на ранних стади-

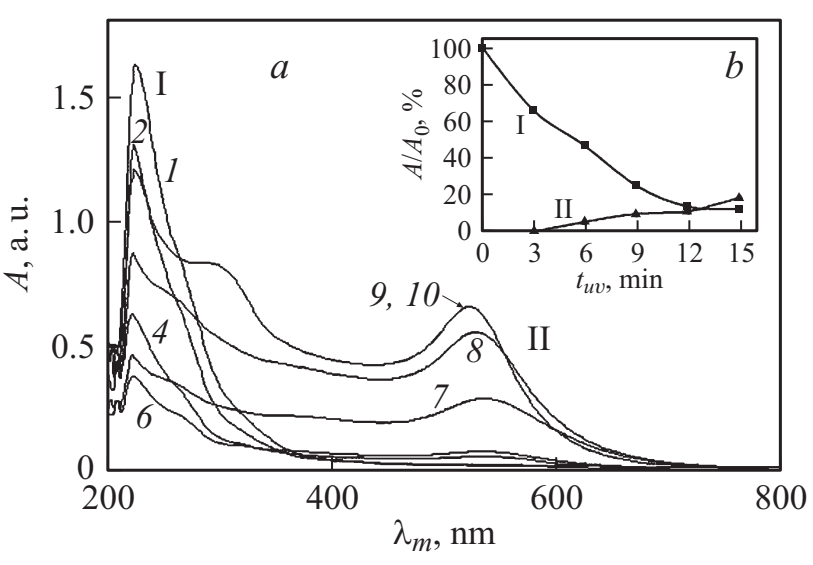

Рис. 1. Оптические спектры нанодисперсий (номера кривых соответствуют номерам образцов в таблице) (a); относительная интенсивность пиков I и II на ранних стадиях синтеза $(b)$. 
ях формирования, когда концентрация НЧ невелика, интенсивность малоуглового рассеяния от НЧ золота сопоставима с рассеянием от полимерной матрицы [6].

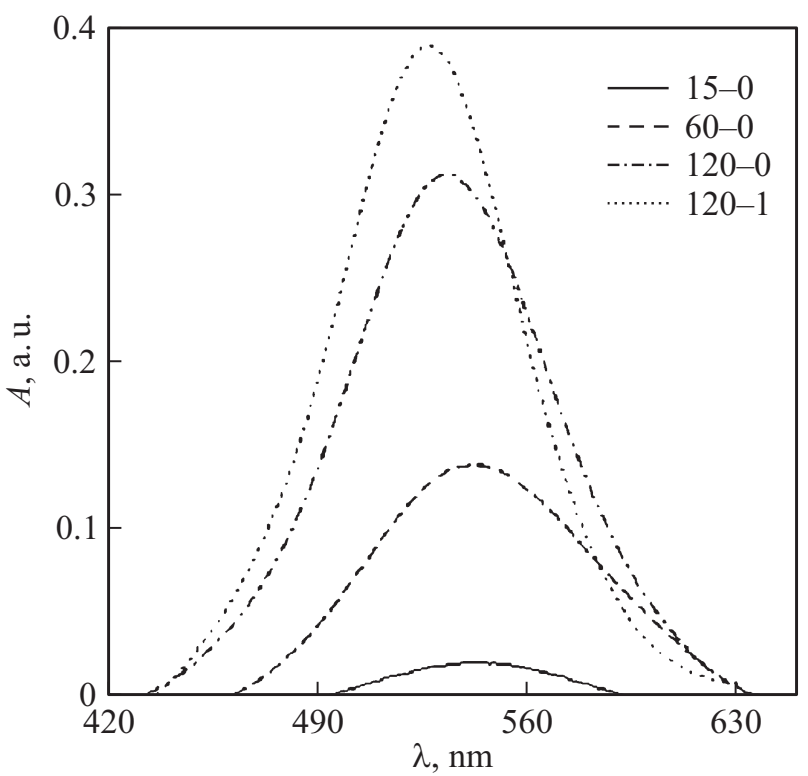

Pис. 2. Пики плазмонного поглощения после вычитания фона.
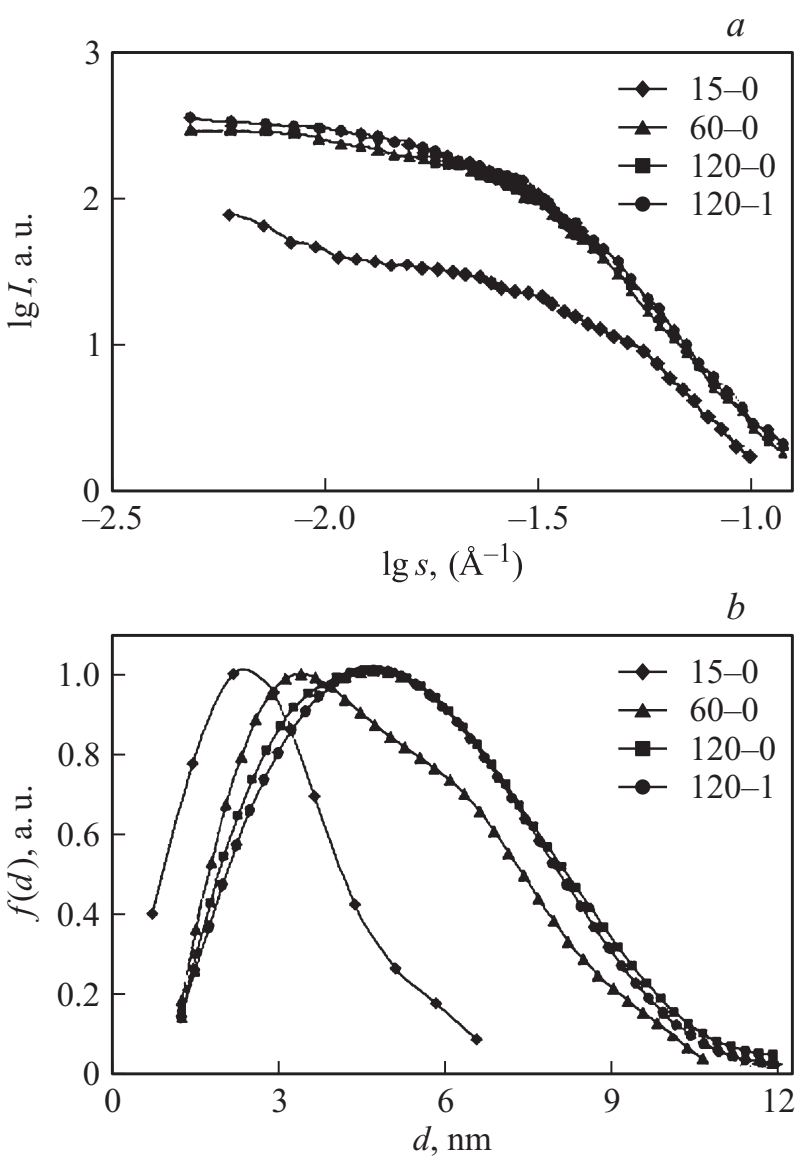

Рис. 3. Кривые малоуглового рассеяния в координатах $\lg I-\lg s(a)$, распределения по размерам $(b)$ для НЧ золота, формирующихся в уксуснокислых растворах хитозана.

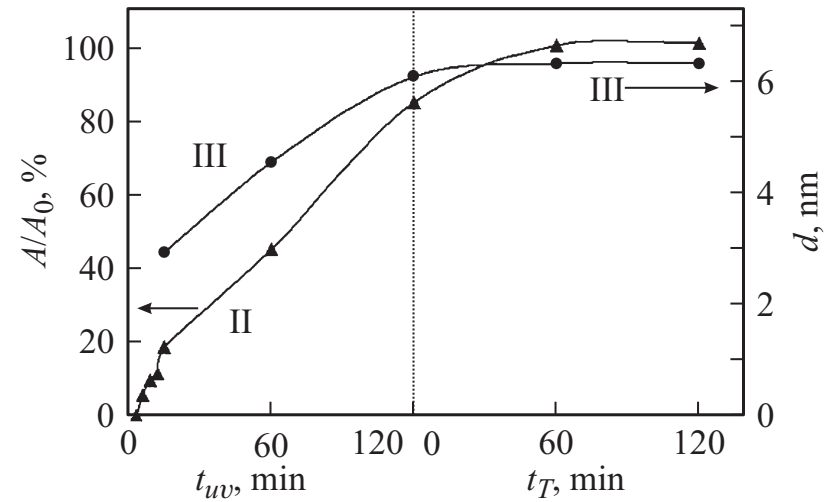

Рис. 4. Зависимость относительной интенсивности пика ПР (кривая II) и среднего размера НЧ (кривая III) от времени синтеза.

Последняя определялась экспериментально и вычиталась из кривых МУРР для нанодисперсий. Увеличение концентрации НЧ в ходе синтеза сопровождается существенным ростом интенсивности рассеяния на НЧ, вклад от матрицы становится пренебрежимо малым. Угловые зависимости интенсивности малоуглового рассеяния $I(s)$, где $s$ - вектор дифракции, представленные на рис. $3, a$, относятся только к НЧ.

Качественный анализ кривых МУРР позволяет придти к выводу, что формирование НЧ проходит в два этапа. Первый характеризуется быстрым ростом интенсивности рассеяния и существенным изменением формы $I(s)$, что обусловлено одновременным увеличением и концентрации НЧ, и их размеров. На втором этапе наблюдается изменение так называемых „внутренних“ (вблизи первичного пучка) участков кривых. Спад интенсивности к минимальным значениям описывается степенным законом с показателем степени, равным -3 , что характерно для экспериментальных зависимостей $I(s)$, полученных при щелевой коллимации первичного пучка [21]. После окончания процесса формирования $\left(t_{U V}=120 \mathrm{~min}\right.$, $t_{T}=1 \mathrm{~h}$ прогрева) кривые малоуглового рассеяния остаются неизменными, система НЧ является стабильной. Определенные методом МУРР средние размеры НЧ $d$ приведены в таблице, распределения НЧ по размерам $f(d)$ - на рис. $3, b(f(d)$ вычисляли по программе GNOM [22]).

При изменении времени УФ облучения от 15 до 60 min средний размер сформировавшихся НЧ увеличивается от 2.9 до $4.5 \mathrm{~nm}$, распределение по размерам несимметрично уширяется. Далее рост НЧ золота замедляется. На рис. 4 показана эволюция пика ПР и среднего размера НЧ при различных временах УФ воздействия и прогрева.

Доминирующий механизм роста НЧ золота на различных этапах синтеза был установлен путем анализа формы кривых распределения по размерам, соответствующих определенному времени. При последовательном росте число атомов в каждой последующей частице 
определяется суммой арифметической прогрессии. При случайном процессе присоединения атомов, происходящем с равной вероятностью, размеры частиц в сформировавшемся полидисперсном ансамбле подчиняются нормальному (гауссовому) закону распределения:

$$
f(x, \bar{x}, \sigma)=\frac{1}{\sqrt{2 \pi} \sigma} e^{-\frac{1}{2}\left(\frac{x-\bar{x}}{\sigma}\right)^{2}},
$$

где $x$ - размер частиц, $\bar{x}-$ средний (соответствующий максимуму распределения) размер частиц, $\sigma$ - параметр, характеризующий ширину распределения.

Для второго механизма была разработана простая статистическая модель, представляющая рост частиц в виде последовательного ряда дискретных событий, в каждом из которых объединяются только два кластера, причем объем одного из них составляет случайную долю объема результирующей частицы. Число атомов в частице описывается суммой геометрической прогрессии. В пределе очень большого числа событий было получено логарифмически нормальное распределение частиц по размерам:

$$
f(x, \bar{x}, \sigma)=\frac{1}{\sqrt{2 \pi} x \sigma} e^{-\frac{1}{2}\left(\frac{\ln x-\ln \bar{x}}{\sigma}\right)^{2}} .
$$

Здесь обозначения соответствуют аналогичным в формуле (1).

В работе [19] показано, что асимметричное распределение частиц по размерам характерно для процесса роста частиц, контролируемого либо поверхностной диффузией, либо реакцией на поверхности частиц. Экспериментально подтверждено [20], что при самых разных способах синтеза НЧ часто формируются полидисперсные ансамбли с логарифмически нормальным распределением частиц по размерам. Однако в общем случае в зависимости от способа и режимов синтеза действуют различные механизмы и формируются металлические НЧ, имеющие некое распределение по размерам. Изменение вида распределения частиц по размерам в процессе роста свидетельствует о смене доминирующего механизма.

Стандартным методом проверки гипотезы нормального распределения случайной величины является обратное нелинейное преобразование функции плотности вероятности [19]. При этом строится функция ошибок распределения случайной величины $\operatorname{Erf}(x)$ и далее осуществляется нелинейное преобразование оси ординат таким образом, чтобы величина, пропорциональная значению $\operatorname{Erf}(x)$, определяемая выражением (3), приобрела линейный вид:

$$
\operatorname{Erf}(x)=\frac{2}{\sigma \sqrt{\pi}} \int_{0}^{x} e^{-t^{2}} d t .
$$

Для всех исследованных образцов были построены графики в координатах $\operatorname{Erf}(d)-d$ и $\operatorname{Erf}(d)-\lg d$ и определе-
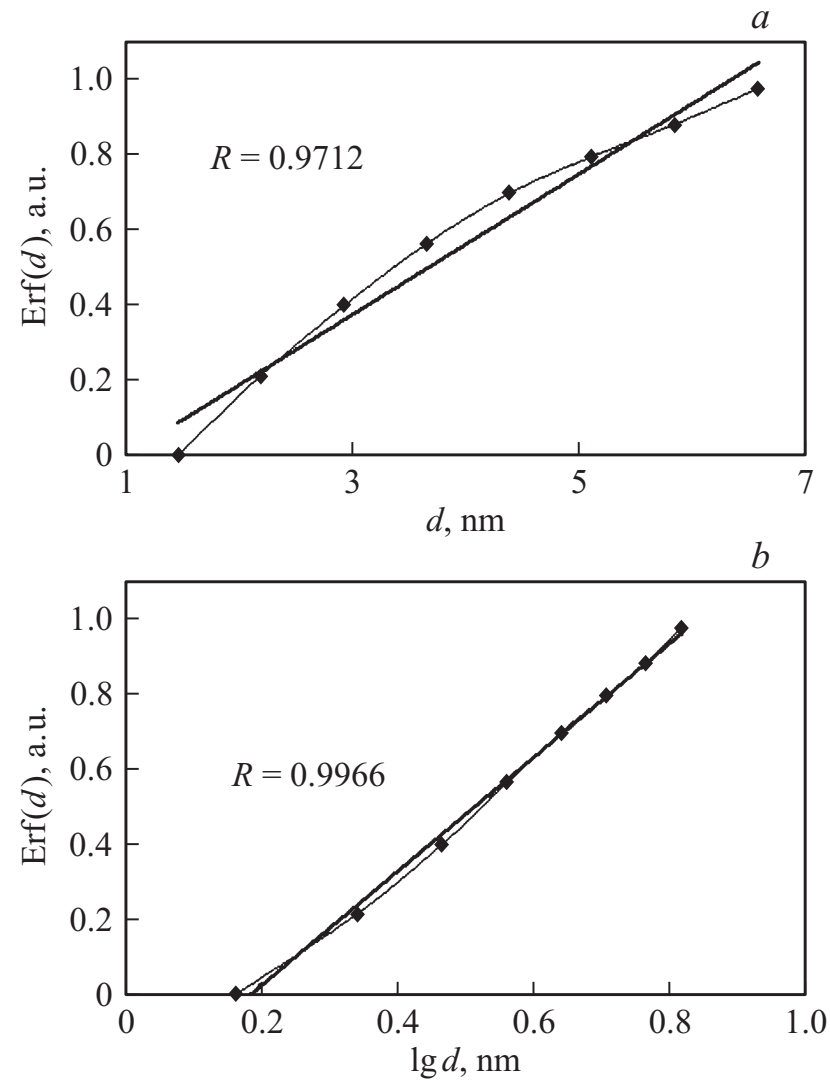

Рис. 5. Зависимость нормализованной функции ошибок Erf от размера частиц $d$ в координатах $\operatorname{Erf}(d)-d(a)$ и в координатах $\operatorname{Erf}(d)-\lg d(b)$ для образца 15-0.

ны соответствующие коэффициенты корреляции $R$ (таблица). На рис. 5 в качестве примера приведены зависимости $\operatorname{Erf}(d)-d$ и $\operatorname{Erf}(d)-\lg d$ для одного из образцов.

Выполнен совместный анализ результатов оптической спектроскопии и малоуглового рассеяния рентгеновских лучей, которые одновременно использовались для изучения кинетики процесса формирования НЧ золота. В процессе синтеза максимум ПР непрерывно смещается в сторону меньших длин волн, в то время как средний размер частиц монотонно увеличивается с течением времени синтеза (таблица). Этот факт на первый взгляд находится в противоречии с рядом отечественных и зарубежных публикаций, которые подтверждают прямо пропорциональную зависимость между положением максимума ПР и средним размером металлических НЧ $[7,23]$. Но следует отметить, что данные этих работ относятся к полностью сформировавшимся равновесным системам. Результаты, согласующиеся с полученными в настоящей работе, приводят авторы [24], которые отмечают сдвиг максимума ПР в сторону меньших длин волн в процессе роста НЧ никеля и серебра. Они высказывают предположение, что на начальном этапе взаимодействия золей $\mathrm{Ni}$ с ионами серебра образуются нестабильные агрегаты $\mathrm{Ni}-\mathrm{Ag}$, при распаде которых средний размер НЧ уменьшается, что является причи- 
ной смещения пика ПР в область меньших длин волн, однако экспериментальных доказательств существования агрегатов не приводится.

Согласно теории [7,23], одной из возможных причин смещения максимума плазмонного резонанса металлических НЧ в коротковолновую область является уменьшение диэлектрической проницаемости среды $\varepsilon_{m}$. Полученные нами ранее результаты по исследованию диэлектрических свойств нанодисперсий методом релаксационной спектроскопии [25] показали, что диэлектрическая проницаемость $\varepsilon_{m}$ существенно уменьшается со временем синтеза, минимальное значение $\varepsilon_{m}$ соответствует полностью сформировавшейся нанокомпозиции. Следовательно, именно с этим фактом можно связать наблюдаемое для нанодисперсий смещение пика ПР в сторону меньших длин волн при одновременном увеличении среднего размера НЧ.

Анализ результатов метода МУРР свидетельствует, что на ранних этапах синтеза доминирующим является „параллельный“ механизм роста НЧ. Очевидно, при достаточно высокой концентрации атомарного золота происходит образование кластеров из единичных атомов, далее включаются процессы коалесценции и последующей коагуляции уже сформировавшихся кластерных фрагментов. С увеличением времени УФ воздействия соотношение коэффициентов корреляции говорит о переходе от „параллельного“ механизма роста НЧ к смешанному. На завершающей стадии синтеза доминирующим становится ,последовательный“ механизм роста НЧ.

\section{Заключение}

Экспериментально зафиксированы изменения оптических и структурных параметров полимерных нанодисперсий от времени синтеза. Установлено, что увеличение среднего размера НЧ золота с течением времени сопровождается смещением максимума плазмонного резонанса в сторону меньших длин волн. Предложено возможное объяснение данного эффекта.

Путем анализа прямых экспериментальных данных функций распределения НЧ по размерам, полученных методом МУРР, - доказана смена механизма в процессе роста НЧ.

Показано, что использование двух взаимодополняющих методов диагностики структуры и свойств наносистемы в процессе формирования НЧ: оптической спектроскопии и малоуглового рассеяния рентгеновских лучей, позволило детально описать рост НЧ золота в полимерных дисперсиях на основе хитозана.

Работа выполнена при частичной финансовой поддержке Министерства образования и науки Российской Федерации (проект № 4.3760.2017).

\section{Список литературы}

[1] Srivastava S., Haridas M., Basu J.K. // Bull Mater. Sci. 2008. Vol. 31. P. 213-217.

[2] Оленин А.Ю., Лисичкин Г.В. // Успехи химии. 2011. Т. 80. C. 635-662.

[3] Коршунов А.В., Кашкан Г.В., Нгуен Х.Т.Т., Зыонг Ш.В. // Изв. Томского политех. ун-та. 2011. Т. 318. С. 12-18.

[4] Богданов А.А., Поздняков А.О. // Письма в ЖТФ. 2014. T. 40. C. $1-5$.

[5] Смирнова Л.А., Грачева Т.А., Мочалова А.Е. идр. // Российские нанотехнологии. 2009. Т. 4. С. 44- 47.

[6] Грачева Т.А., Кузьмичева Т.А., Перевезенцев В.Н. идр. // Поверхность. 2011. Т. 5. С. 21-25.

[7] Хлебцов Н.Г., Богатырев В.А. // Российские нанотехнологии. 2007. Т. 2. С. 69-86.

[8] Корягин А.С., Мочалова А.Е., Саломатина Е.В., Ешкова О.Ю., Смирнова Л.А. // Перспективные материалы. 2012. № 5. C. 53-57.

[9] Fasla B., Senoudi A.R., Boussaid A., Benmouna M., Benmouna R. // J. Biomater. Nanotech. 2011. Vol. 1. P. 49-54.

[10] Shengchun Yang, Yaping Wang, Qingfeng Wang, Ruili Zhang, Bingjun Ding // Colloid. Surf. A. 2007. Vol. 31. P. 174-183.

[11] Kreibig U., Bour G., Hilger A., Gartz M. // Phys. Status Solidi A. 1999. Vol. 175. P. 351-366.

[12] Образцов П.А., Нащекин А.В., Никоноров Н.В., Сидоров А.И., Панфилова А.В., Брунков П.Н. // ФТТ. 2013. Т. 55. C. $1180-1186$.

[13] Рыбалтовский А.О., Илюхин С.С., Минаев Н.В., Тимашев П.С., Юсупов В.И., Баграташвили В.Н. // Российские нанотехнологии. 2014. Т. 9. С. 6-10.

[14] Binghui Wang, Xupin Zhuang, Wenjian Deng, Bowen Cheng // Engineering. 2010. Vol. 2. P. 387-390.

[15] Аммон Л.Ю. // Нанотехника. 2011. № 2. С. 93-96.

[16] Рогов А.В., Фанченко С.С. // ЖТФ. 2012. Т. 82. № 2. C. 129-135.

[17] Wiley B., Sun Y., Mayers B., Xia Y. // Chem. Eur. J. 2005. Vol. 11. P. 454.

[18] Yi H.-B., Diefenbach M., Choi Y.C., Lee C.E., Lee H.M., Hong B.H., Kim K.S. // Chem. Eur. J. 2006. Vol. 12. P. 4885.

[19] Granqvist C.G., Buhrman R.A. // J. Appl. Phys. 1976. Vol. 47. N 5. P. $2200-2219$.

[20] Оленин А.Ю. // Российские нанотехнологии. 2012. Т. 7. C. $53-55$.

[21] Свергун Д.И., Фейгин Л.А. Рентгеновское и нейтронное малоугловое рассеяние. М.: Наука, 1986. 278 с.

[22] Svergun D.I. // J. Appl. Cryst. 1992. Vol. 25. P. 495.

[23] Борен К., Хафмен Д. Поглощение и рассеяние света малыми частицами. М.: Мир, 1986. 664 с.

[24] Ершов Б.Г. // Российский хим. журн. 2001. Т. 45. С. 20.

[25] Автореф. канд. дис. Кузьмичева Т.А. Золотосодержащие полимерные нанокомпозиции: структурообразование, свойства и диагностика. 2013. Нижний Новгород. 115 с. 